102

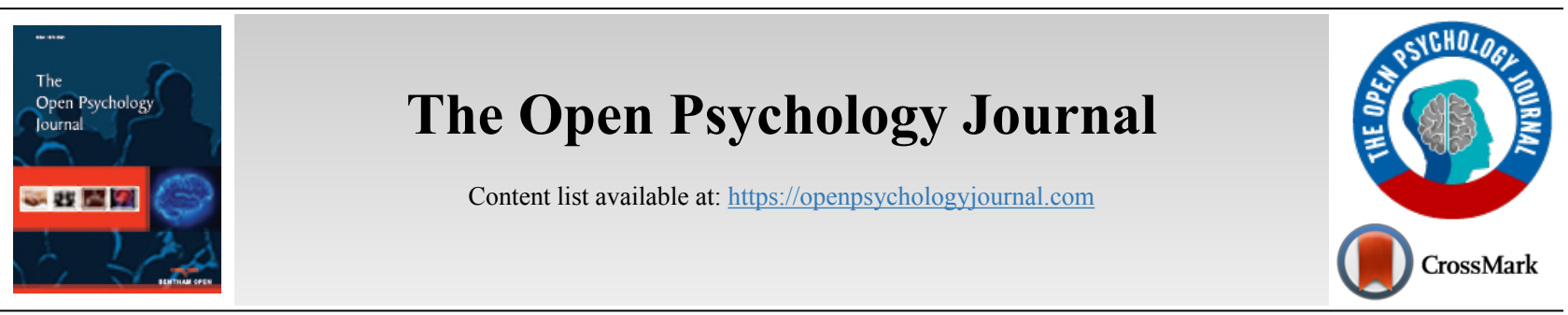

RESEARCH ARTICLE

\title{
A New Model of Subjective Well-Being
}

\author{
Igor Kopsov $^{*}$ \\ Fürstveien 5A, 1367 Snarøya, Norway
}

\begin{abstract}
:
Background:

We propose a new approach to evaluation of SWB, which we specify as a combination of two states, momentary SWB and projected SWB. The former is a measure of satisfaction with transient life experiences, the latter a reflection of expected probability of satisfaction of future aspirations. These two states, independent, but complementary to each other, consist of distinct components associated with different human needs.

\section{Methods:}

By postulating need satisfaction as the sole course of attainment of happiness, it allows us to define SWB through functional equations that link level of attained SWB to a need satisfaction ratio, a need ranking, and an estimated probability of future need satisfaction.

\section{Findings:}

Subsequently, we present a model of SWB through the lens of our proposed algorithm of human behaviour, which demonstrates the needs satisfaction process. The algorithm consists of several interdependent phases and feedback mechanisms. The theorized feedback mechanisms result in a continuous redefinition of dominant needs due to needs satisfaction. Feedback mechanisms create dynamic and non-linear interrelations between needs, the degree of their attainment and subsequent happiness.

\section{Conclusion:}

Through this approach, we explain such phenomena as deflation of happiness, psychological adaptation to hardship, and multiplicity of strategies to attain happiness. The proposed model allows integration of a number of existing SWB theories into a unified concept.
\end{abstract}

Keywords: Algorithm of human behaviour, Happiness, Human behaviour, Needs, Subjective well-being, Theory of happiness.

\begin{tabular}{l|l|l|l} 
Article History & Received: January 19, 2019 & Revised: February 10, 2019 & Accepted: February 18, 2019
\end{tabular}

\section{INTRODUCTION}

The human desire to attain happiness has plausibly existed since the dawn of humanity, and verifiably since at least the times of ancient Greece. As pointed by Lyubomirsky [1], it may be argued that its steadfast pursuit is more vigorous today than ever, both in Western societies, where the term itself is foundational in the constitution and culture of the United States of America and in other societies across the world, where the pursuit of the concept has become apparent. It may be feasibly argued that well-being itself is a worthwhile goal, because happiness not only feels good, but also has tangible benefits for individuals who experience it as well as for their friends, families, immediate communities, and, consequentially for society at large.

\footnotetext{
* Address correspondence to this author at the Fürstveien 5A, 1367 Snarøya, Norway; Tel: + 47 48088517; E-mail: ikopsov@gmail.com
}

Diener [2] estimates that the number of scientific articles on Subjective Well-Being (SWB) has multiplied in recent years, from ca. 130 articles published per annum in 1980 to more than 1,000 published per month more recently. However, even as the number of scientific studies of SWB has grown exceptionally in the last 40 years, the concept of happiness remains elusive, reflected in the current trends of moving away from descriptive and parametric analyses of happiness to the creation of models of happiness. Csikszentmihalyi in his theory of flow [3] conceptualised happiness as a balance between encountered challenges and availability of skills to face them. Sheldon \& Lyubomirsky [4] developed a Hedonic Adaptation Prevention model which theorises happiness as a balance between present-oriented (i.e. living in the present) and forward-looking (i.e. creating expectations about the future) living. Dodge et al. [5] define well-being as a balance between resources and challenges. Veenhoven [6], following in Maslow's [7] footsteps, proposes a model of happiness that is 
based on the satisfaction of experienced needs.

In our view, these models tend to firmly emphasise specific components of well-being. In this paper, we attempt to develop a generic model of SWB by postulating that the concept of SWB should be based on the model of human behaviour. As behaviour manifests itself through actions, then the level of SWB should reflect the level of success of actions undertaken by an individual. It is important to emphasise that we ascertain actions not through simplified lenses of behaviourism, but from a perspective of constantly transforming personality put in the ever changing physical and social contexts. We attempt to develop an algorithm of human behaviour and based on it propose a formulation of SWB, initially only for the transient experience and, then for the long-term perspective of human existence. We will identify separable components of SWB associated with different needs and time perspectives. We will examine main factors affecting SWB and discuss variations in strategies for the attainment of happiness. In doing so our focus will be on the processes of change in happiness and not on the computation of levels of happiness.

\section{SWB AND AN ALGORITHM OF HUMAN BEHAV- IOUR}

\subsection{Happiness vs. Subjective Well-Being}

An early contemporary definition of happiness was proposed by Wilson in 1967 in the paper "Correlates of avowed happiness" [8]. Two years later Bradburn published "The structure of psychological well-being" [9], which has later become regarded as an important contribution to the study of well-being. Although, Bradburn uses the term psychological well-being in the title of his work, he also refers to this term as happiness. Bradburn links happiness to Aristotle's idea of Eudaimonia, commonly translated as well-being [5]. Since then the usage of the term of well-being has been further expanded and the term Subjective Well-Being (SWB) was coined in scientific literature. Eventually, the ambiguity of defining happiness in historical and cultural perspectives caused social scientists to opt further towards the usage of the term subjective well-being as opposed to happiness [10]. However, it appears that ambivalence may be related not to the usage of a specific term, but more to the subject it denotes. Thus, Dodge et al. in the paper appropriately entitled "The challenges of defining wellbeing" point to the ambiguity in defining SWB [5]. This challenge is echoed by Forgeard et al., who noted that "the question of how wellbeing should be defined (or spelt) still remains largely unresolved, which has given rise to blurred and overly broad definitions of wellbeing" [11].

Helliwell et al., in discussing the application of the term happiness $v s$. SWB note that three main strands of arguments have been expressed against the use of happiness, as opposed to SWB [12]. Firstly, it is criticised for being narrow, since happiness is one of many emotions, so that it may be confusing to use it to cover the broader range of measures that humans experience. Secondly, it is criticised for its breadth, since the appearance of happiness both as an emotion and as a form of evaluation may risk confusion. Thirdly, there are concerns that the usage of the term happiness invites dismissal for its apparent flakiness - a topic to joke about, or to ignore for not being sufficiently serious. On the other hand, the United Nations (UN) General Assembly Resolution [13], the Bhutanese government's national objective of maximisation of Gross National Happiness, and the Ministry of Happiness of the United Arab Emirates government are all institutions that explicit in their focus on happiness and its development. Helliwell et al. [12] advocate for the usage of the term happiness as it is arguably more widely understood rather than the more technical description of subjective well-being. The preference towards the usage of happiness as a synonym for SWB is not limited to political and popular texts, but also widely applied in scientific literature $[1,14]$. As such, in this paper, we use the term happiness as a synonym for SWB.

\subsection{Definition of SWB}

Definition of the subject is the first step to establishing a conceptual model. Dodge et al. performed a multi-disciplinary review of past efforts to define well-being [5]. They conclude that the question of how to define well-being remains unanswered and that numerous attempts to do so have resulted only in a description of well-being rather than a definition. An example of the descriptive approach can be found in work by Diener et al. [15], who theorise that "SWB is a broad category of phenomena that includes people's emotional responses, domain satisfactions, and global judgments of life satisfaction. Each of the specific constructs need to be understood in their own right, yet the components often correlate substantially, suggesting the need for the higher order factor. Thus, we define SWB as a general area of scientific interest rather than a single specific construct".

However, in their later work, Diener defines SWB as a person's cognitive and affective evaluation of his or her life [16], and this has become the most widely accepted definition. Notably, it is closely related to the definition of happiness provided by the modern Webster Unabridged Dictionary. It is also reflected in the OECD (2013) "Guidelines for the Measurement of Subjective Well-being" [17], which quotes the following recommendation from the Commission on the Measurement of Economic and Social Progress: "SWB encompasses three different aspects: cognitive evaluations of one's life, positive emotions (joy, pride), and negative emotions (pain, anger, worry)".

Diener et al.'s [16] definition provide a solid foundation for developing a model of SWB by identifying its main components (cognitive and affective), and referring to the evaluation process, which implies the existence of criteria for such evaluation. Historically, the science of happiness was predominantly about ways to enhance happiness, however, the question of criteria of happiness has always remained in the background. For example, Shin and Johnson describe wellbeing as a "global assessment of a person's quality of life according to his own chosen criteria" [18]. The reference to "his own criteria" is too vague to be used for any practical application. Furthermore, the definition of life is in itself controversial, as many definitions have been proposed depending on the field of science and context. McKay argues that in regard to the existence of an individual, life can be defined as the history of activities that an organism undertakes 
[19]. Hence, the criteria for evaluation of a person's life should be based on the degree of success of the activities undertaken by an individual. Consequently, any model of SWB, where the degree of SWB arises as a consequence of one's evaluation of life and outcome of activities, must be centred on the analysis of human behaviour.

\subsection{Algorithm of Human Behaviour}

We refer to well-being not as a stand-alone phenomenon but as reflection and result of life progression. Similar to life, SWB is not a state but an outcome of a dynamic process, which should be examined through the lenses of characteristics of human behaviour. Human conduct, in turn, is a course of activities governed by social, physiological, cognitive and physical incentives. Hence, understanding SWB requires us to understand the underlying mechanism that initiate, control and gratify human behaviour.

Concepts with variable degrees of concretisation of an algorithm, i.e. a process or set of rules that are followed, of human behaviour have been developed within different branches of psychology and social sciences. For instance, Galperin conceptualised human behaviour as a sequence of actions, with each action consisting of four primary steps: 1) establishment of a model (image) of the field of operations, 2) clarification of the utility links between the field of operations and dominant needs, 3) development of a solution plan, and 4) control of execution of the action with implementation of necessary corrections [20]. The most advanced models of human behaviour have been established within the frameworks of cognitive psychology and unified theory of cognition [21, 22]. Within the premise of these concepts, human cognition is modelled as a system consisting of memory, decision-making, and goal blocks, and which receives input from the perceptual (sensory) subsystem, and provides output to the motor (execution) subsystem. One of the most widely utilised event-processing and decision-making theories was formulated by military strategist John Boyd in application to combat operations, and which was later extended to a variety of applications, including commercial operations, learning processes and litigation [23]. At the core of Boyd's theory is the concept of the OODA loop, which defines a decision cycle as consisting of four primary steps; Observe, Orient, Decide, and Act. More recently, considerable progress in modelling human behaviour was achieved with the framework of the theory of reasoned action, which explains the relationship between attitudes and behaviours within human action [24].

Even though these concepts have been developed for a range of applications and purposes they all consist of common blocks on which an algorithm of human behaviour can be defined: i.e. 1) signal detection (observation, perception or establishment of a model of the field of operation), 2) orientation (clarification of the utility links between the field of operations and dominant needs), 3) decision (planning), and 4) action execution. Any algorithm must differentiate between linear operational steps and decision making gates. The latter allows for multiple outcomes and subsequently plays a key role in any process. In order to more precisely identify the decision making gates of various functionalities within the algorithm of human behaviour, we further split the orientation block into two separate phases; signal assessment and risk analysis. Based on this, we conceive an algorithm of human behaviour presented in Fig. (1), and summarised in the following paragraphs.

The reason for any action is a need or combination of needs, which humans experience a great amount of. In the algorithm we equate needs with wants. Needs are inborn and universal, whilst wants are acquired and can vary across cultures, but they have the same role in the mechanism of instigation of actions. In the context of specific life circumstances, only a limited set of so called dominant needs [20], those that are essential to existence, is manifested in a person at any given time.

At all moments individuals experience a range of intrinsic and extrinsic body signals. Each signal is immediately subjected to an assessment in order to determine whether it is relevant to the satisfaction of any dominant need. Based on the result of the signal assessment, risk analysis is performed for possible action scenarios. Risk analysis is carried out based on life experience, which also includes attitudes, norms, and perceived behavioural control [24]. Humans rate the likelihood of potential gains and losses of an action against the criticality of a given need. In most instances, a decision is driven by the outcome of the evaluation of estimated required energy expenditure versus estimated utility gain. The analysis also addresses the potential consequences of the outcome of the worst case scenario. If gains are assessed to be substantial, possible failures manageable and estimated energy expenditure acceptable, the individual proceeds to the next step of the decision making process. Otherwise, a potential action is abandoned.

If based on the risk analysis a go-ahead is given, the next step is to plan the action. If the goal can be achieved in a variety of ways, multiple iterations between risk analysis and planning phases may be required prior to determining the way forward.

The final phase is action execution, which is based on the predetermined plan. As the action progresses, new signals are received and evaluated, and behaviour is subsequently readjusted accordingly with the new information gained. Human life is a continuous chain of actions executed in accordance with the described standard algorithm. Important to emphasise, that we ascribe actions not in behaviouristic way but within a broader context, with actions being responses to an entire range of physiological, psychological and social needs, including needs of eudaimonic dimensions.

Besides the execution sequence "signal detection assessment - risk analysis - plan - action" the behavioural algorithm includes regulating blocks controlling the assessment and risk analysis steps; i.e. A catalogue of dominant needs and an experiences database.

The catalogue of dominant needs is defined by intrinsic life circumstances. At any given time, it is fluid and versatile, and always reflects the outside environment and subjective state of an individual's psyche. It may be described as the "engine" of 


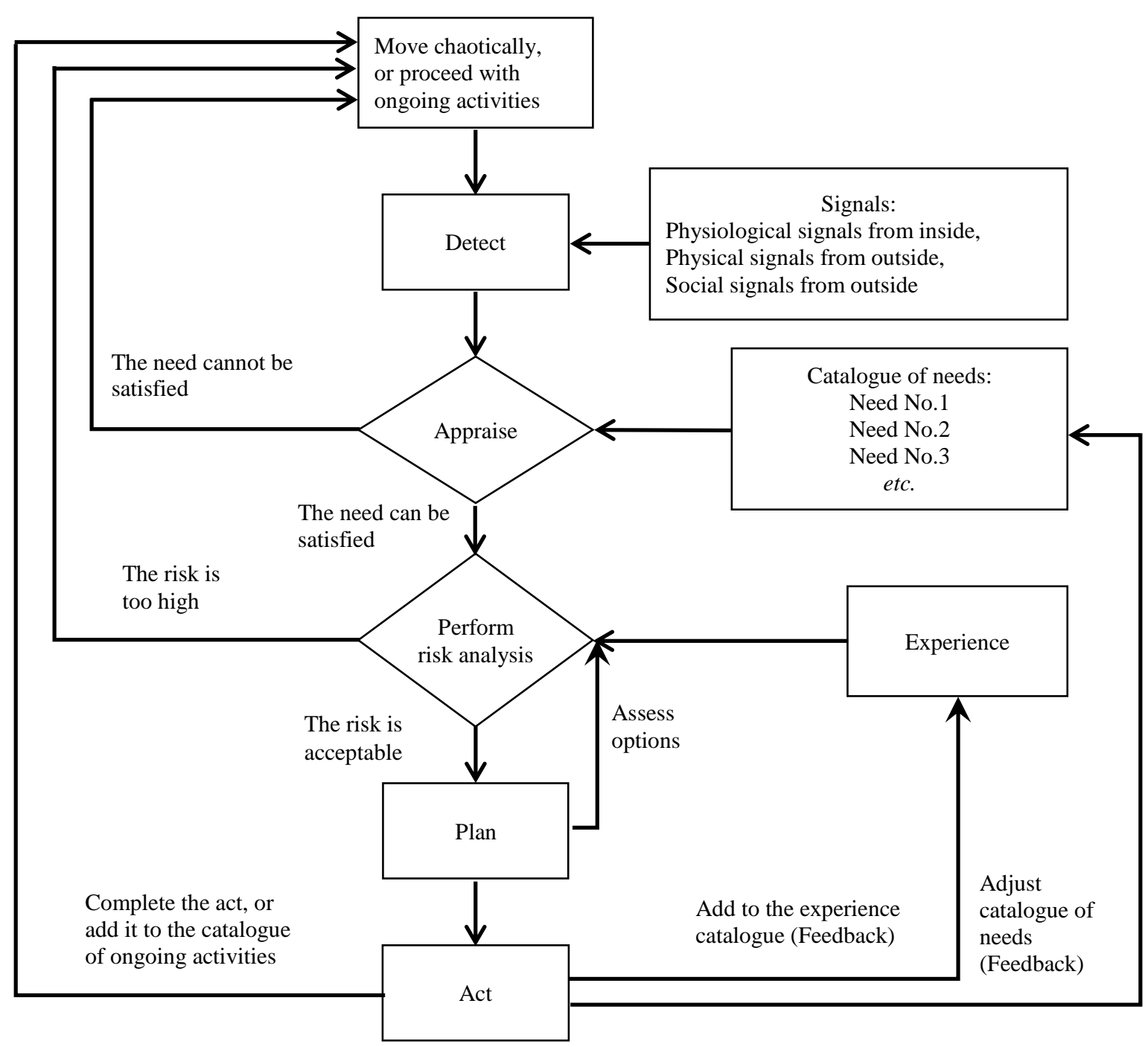

Fig. (1). Algorithm of Human Behaviour.

the algorithm, which triggers any undertaken activity. When intent towards an activity is instigated by needs, it is subsequently subject to a risk analysis that is performed based on an individual's life experiences. Each individual has a "repository" of past experiences, completed actions and their outcomes. This repository is different in all individuals, and we refer to it as the experience database. It stores and remembers practical lessons learnt, and consolidates attitudes, norms, and cultural predispositions. The experience database is dynamic, continuously updated and altered throughout life.

Actions are initiated, and subsequently executed, due to and based on dominant needs and the experience database. In turn, outcomes of actions form the experience database and redefine the catalogue of needs, which triggered actions in the first place. As such, the components of the behavioural algorithm are interlinked by feedback mechanisms. Per Fig. (1), the algorithm includes several such feedback loops; 1) risk analysis - plan - risk analysis; 2) risk analysis - action - life experience - risk analysis; 3 ) catalogue of dominant needs - action - catalogue of dominant needs. Feedback loops continuously generate updates resulting in dynamism of human cognitive and emotional states. Individuals always exist in a state of unbalance that requires continuous effort and adjustment to preserve and continue the existence of an organism. The behavioural algorithm represents a dialectical model of human development and incorporates non-linear interactive dynamism between individuals and their environment.

\section{MOMENTARY PERSPECTIVE OF SWB}

Since activities are instigated for the purpose of their successful completion, one can envisage that SWB correlates with success of actions. Therefore, we will attempt to use proposed algorithm of human behaviour to establish a model of SWB, starting first with the transient state of life related to specific evets or experiences.

Individuals evaluate needs independently from each other, as pointed by Tay \& Diener [25], who "found evidence of universality and also substantial independence in the effects of 
the needs on SWB". As "observed needs tend be achieved in a certain order but that the order in which they are achieved does not strongly influence their effects on SWB. Motivational prepotency does not mean that fulfilling needs 'out of order' is necessarily less fulfilling. Thus, humans can derive 'happiness' from simultaneously working on a number of needs regardless of the fulfilment of other needs". Every undertaken action results in a change (however miniscule) in the level of SWB. Successfully executed actions (where a positive outcome is achieved) enhance SWB levels, and vice versa unsuccessful actions have an adverse effect on SWB. We define changes in the instant level of SWB caused by an action as a variation in momentary SWB $\Delta \mathbf{H}_{\mathrm{m}}$. Its magnitude is proportional to the relative weight $\boldsymbol{w}_{i}$ of the need which triggers the action. In our formula, the value of the relative weight of an individual need has a value between 0 and 1 , and the combined sum of all relative weights of needs is 1 , i.e.:

$$
\sum_{i=1}^{m} w_{i}=1
$$

Where: $m$ - the total number of needs of an individual.

Therefore, as an example, successful execution of an action aimed at the satisfaction of a higher-weighted need results in a greater level of SWB. Not all actions have successful outcomes; some only partially achieve their objectives, and others may result in adverse impacts on life conditions. Hence, the change in the level of SWB upon completion of an action must be proportional to the achievement ratio $\boldsymbol{k}_{\boldsymbol{i}}$. The achievement ratio is 1 if a need is fully satisfied and 0 if the need is not satisfied at all. Furthermore, intermediate states of success arise when a need is partially satisfied, for example, when a person aspiring for a work promotion receives assurances that it will happen, but is conditioned upon achieving certain additional realistic criteria. Depending on the subjective evaluation of these conditions, a person may perceive that in the given moment the need is partially satisfied and allocate it a ratio of achievement $\boldsymbol{k}_{i}$, which is less than 1 (e.g. partial fulfilment). There are also actions producing adverse results. A worst-case scenario is when an action results in the termination of a need, i.e. makes it impossible to satisfy it. In this case the achievement ratio $\boldsymbol{k}_{\boldsymbol{i}}$ equals -1 . As an example, imagine failing a university examination which results in expulsion, thus making the need to pass exams and obtaining a degree obsolete (or much more difficult to such an extent that it becomes unrealistic). Hence, for any given action the ratio of achievement can be within the range between -1 and 1 . As it follows from the definition of SWB, evaluation of each action encompasses affective (emotional) and cognitive components. Therefore, the change in level of SWB $\Delta \mathbf{H}_{\mathrm{m}}$ as a result of an action addressing a specific need is a function of the need's relative weight and the ratio of its satisfaction. It can be defined as:

$$
\Delta \mathrm{H}_{\mathrm{m}}=\boldsymbol{F}_{\text {affective }}\left(\boldsymbol{Y}_{i} \boldsymbol{k}_{i} \boldsymbol{w}_{i}\right)+\boldsymbol{F}_{\text {cognitive }}\left(\boldsymbol{Y}_{i} \boldsymbol{k}_{i} \boldsymbol{w}_{i}\right)
$$

$\Delta \mathrm{Hm}$ - impact of action on the level of SWB in regard to need $i$,

Faffective - affective component of impact of an action on the level of SWB,

Fcognitive - cognitive component of impact of an action on the level of SWB,

$k i-$ achievement ratio $(-1 \leq k \leq 1)$,

$w i-$ relative importance weight of the need triggering the action $(0<w<1)$,

\section{$\Upsilon i$ - forgetting factor $(0 \leq \Upsilon \leq 1)$.}

Murray notes that a single action can satisfy more than one need [26]. For instance, victory in a sports competition may to different degrees satisfy safety, self-esteem, and selfactualisation needs, amongst others. Therefore, the overall impact of an action outcome on the level of SWB is the sum of the achievements for all affected needs:

$$
\Delta \mathrm{H}_{\mathrm{m}}=\sum_{i=1}^{n}\left(\boldsymbol{F}_{\text {affective }}\left(\boldsymbol{Y}_{i} \boldsymbol{k}_{i} \boldsymbol{w}_{\boldsymbol{i}}\right)+\boldsymbol{F}_{\text {cognitive }}\left(\boldsymbol{Y}_{i} \boldsymbol{k}_{i} \boldsymbol{w}_{i}\right)\right)
$$

Where:

$\Delta \mathrm{Hm}$ - total impact of an action on the level of SWB considering all affected needs,

Faffective - affective component of impact of an action on the level of SWB,

Fcognitive - cognitive component of impact of an action on the level of SWB,

$k i$-achievement ratio $(-1 \leq k \leq 1)$,

$w i$ - relative weight of need $i$ triggering the action $(0 \leq w$ $\leq 1)$,

$n$ - number of needs affected by the action,

$\Upsilon i$ - forgetting factor $(0 \leq \Upsilon \leq 1)$.

Actions with similar or identical outcomes do not necessarily produce the same change in the level of SWB $\Delta \mathbf{H}_{\mathrm{m}}$, as the relative weight of a need is significantly dependent on life circumstances. For example, a meal consumed after a period of fasting period is likely to result in a more significant increase in SWB levels compared to the increase induced by consumption of that same meal in a regular day to day circumstance, as the weighting of the need for nourishment is greater in the former case. Eq. 3 reflects this phenomenon, as the relative weight of the need is not a fixed but a variable parameter. Indeed, our catalogue of dominant needs is constantly being updated as some needs are satisfied, and others are made obsolete. The $\Delta \mathbf{H}_{\mathrm{m}}$ parameter provides a snapshot of the change in the level of SWB.

This discrete nature of actions immediately raises the question of what happens to SWB levels after action fulfilment. Actions form a fluid and constantly changing field of activities, and the implications of each action are multiform. Successful completion of an action caused by one need inevitably turns individuals' attention to other, dormant or previously non- 
existent needs and the pursuit of happiness continues [7]. Furthermore, changes in SWB levels depreciate over time. The rate of depreciation varies depending on the nature of the need and life circumstances; a pleasant evening spent in the company of friends can satisfy a need for social belonging for several hours, and being in a romantic relationship may have impact spanning years. Nevertheless, even in the latter case, the residual level of the surge in SWB diminishes over time and trends towards its initial base level [27]. Restoration of initial levels of SWB (base levels) originates in the neural nature of human emotions. Schuyler et al., demonstrated that the restoration of the human brain's neural status after exposure to visual stimuli (pictures, etc.) occurs within seconds [28]. Electrical stimulation of a human brain influences psychological behaviour for a period ranging from tens of minutes to several days, with typical impact lasting 1.5 to 2 hours [29]. It is therefore reasonable to propose that emotional impact caused by an action dissipates in a similar way, in line with the concept of automatic emotion regulation as proposed by Schuyler et al. [28]. In order to take into account depreciation of momentary impact of actions on the overall state of SWB, Eq. 3 includes a "forgetting" factor $\boldsymbol{Y}_{i}$, which makes more relatively recent actions more influential than relatively older completed actions. This factor is also used in the equation of happiness developed by Rutledge et al. [30], who hypothesise that happiness is a function of an action's "certain rewards", "expected values", and the difference between experienced and predicted rewards. These parameters correlate with achievement ratio and relative need weight applied in Eq. 3. Rutledge et al. do not consider separable affective and cognitive components of SWB [30]. This approach may be entirely plausible; however, until recently, little research has been conducted into the interrelation and balance between affective and cognitive components of momentary happiness.

\section{PROJECTED PERSPECTIVE OF SWB}

\subsection{Definition of Projected SWB}

Eq. 3 represents a functional dependency, describing change in momentary happiness occurring as a result of a life event. It deals only with transient experience and the extent of its validity is limited. Further we would reason that the described algorithm of human behaviour provides grounds for modelling well-being components associated with long-term perspectives of human existence and allows us to devise a separate SWB formula addressing this case.

In normal life circumstances, the difficulty level of most activities we are involved with is relatively low: humans utilise only a small portion of their physical, mental and psychological capabilities. The human brain and body can endure relatively extreme conditions that are rarely encountered day to day. However, humans are never fully idle either, and thus we normally exist in a state of partial engagement. Indeed, "stimulus-independent thought" or "mind wandering" appears to be the brain's default mode of operation. Killingworth \& Gilbert conducted a study on the experiences of thousands of individuals as they went about their daily activities, and found that on average, study participants reported their minds to be wandering $47 \%$ of the time [31]. The study suggested that in the mind-wandering state, people reported to be less happy than when they were focussed on an activity.

We conceptualise that in periods when individuals are not fully engaged in implementation of actions, they still continue to be perfectly aware of their dominant needs. The key difference is that many of these needs are projected needs that may require future action to attain, and not immediate needs. Per Fig. (1), the sequence of steps within the standard algorithm of action is: signal detection, signal assessment, risk analysis, action planning, and action implementation. We proposition that the sequence of steps in response to projected needs must be the same as for instant needs with the exception of the implementation stage, which is omitted in case of projected needs. Thus, risk assessment and planning are the concluding steps of the behavioural algorithm for projected needs. Planning is a linear operation, which it is often performed within a loop of iterations in combination with risk analysis. With regard to future actions, planning can only be performed to a limited extent. Unlike planning, risk analysis represents a decision-making gate implying application of different and, at times contradicting, criteria, and requiring allocation of a criticality rating to the input and output parameters in situations of uncertainty. These factors make risk analysis the most complex and crucial stage of the algorithm of human behaviour. We postulate that particularly in the case of projected needs, SWB is determined not by the outcome of the action itself, but by the outcome of the risk assessment of the action, which informs individuals of the probability of successful satisfaction of future needs. Combined with the criticality of the need, this assessment can provide an estimate of the future level of SWB related to a particular future need. Unlike with satisfaction of instant needs, which manifest themselves through distinct actions, projected needs are normally not time bound both in regard to the timing of execution and timing of assessment. Only in the short-term perspective may individuals know the timing of actions aimed at satisfaction of future needs, e.g. a visit to the doctor or presentation of a university graduation thesis. Such near future events may generate separable and instant affective and cognitive responses. In the longer term, individuals do not have knowledge of the timing or even the form of materialisation of actions aimed at the satisfaction of future needs. For instance, individuals commonly do not know how and when they are going to find a romantic partner or succeed with their career aspirations. Nevertheless, individuals make subjective evaluations of their chances of satisfying such future needs. Such evaluations are performed continuously, covering a substantial stretch of the life horizon, and are repeated for all prominent needs based on personal experience. It is plausible to suggest that throughout need assessment humans develop a rather steady and integrated (combining cognitive and affective components) picture of deferred needs and chances of their satisfaction. This represents the total level of SWB, which we define as projected SWB. In predicting future SWB each need is valued at its relative weight of importance $\boldsymbol{w}_{\boldsymbol{i}}$ and estimated probability of its satisfaction $\boldsymbol{p}_{\boldsymbol{i}}$. For all needs combined, we define projected SWB as the sum of all estimated probabilities of the satisfaction of future needs: 


$$
\mathrm{H}_{\mathrm{p}}=\sum_{i=1}^{m} p_{i} w_{i}
$$

\section{Where:} needs,

$\mathrm{H}_{\mathrm{p}}$ - total integrated level of SWB, related to projected $p_{i}$ - estimated probability of fully satisfying need $i(0 \leq p$ $\leq 1)$

$$
\begin{aligned}
& w i \text { - relative weight of need } i(0 \leq w \leq 1), \\
& \mathrm{m} \text { - total number of needs. }
\end{aligned}
$$

Projected $S W B$ coefficient $\mathbf{H}_{\mathrm{p}}$ has a range 0 to 1 , where 0 represents complete unhappiness (i.e. no needs are expected to be at all satisfied) and 1 represents full happiness (all needs expected to be fully satisfied). The sum of the relative weights of all needs is equal to 1 (as per Eq. 1). For any individual, $\boldsymbol{w}_{\boldsymbol{i}}$ and $\boldsymbol{p}_{\boldsymbol{i}}$ are highly subjective, dependent on subjective life circumstances, and influenced by the affective nature of human forecasting, as suggested by Wilson \& Gilbert [32]. Humans may also use analytical, or alternatively, intuitive approaches for assessment of risks and probabilities of their success, thus arriving at different conclusions depending on their states of mind [33, 34]. Nevertheless, available data suggests that individuals rely on their state of mood only if their mood is pronounced but use other salient information about their life in the absence of pronounced mood states [35]. The variable nature of $\boldsymbol{w}_{\boldsymbol{i}}$ and $\boldsymbol{p}_{\boldsymbol{i}}$ parameters allows to consider SWB in the context of changes in the social environment and in personal circumstances. Eq. 4 can also be used in quantifying the wellbeing of social groups. For groups of individuals, parameters defining levels of SWB may be determined within statistical frameworks.

The formula for long term SWB (Eq. 4) establishes a link between psychological modelling and decision-making theories, particularly to the theory of subjective expected utility developed by Savage [36] based on the works of Ramsey [37] and von Neumann [38]. The theory of subjective expected utility combines two subjective concepts: the personal utility function, and personal probability distribution. Savage [36] proposes that if the person making a decision adheres to axioms of rationality, believing an uncertain event has possible outcomes $\left(x_{i}\right)$, each with a utility of $\boldsymbol{u}\left(x_{i}\right)$, then that person's choices can be explained as arising from this utility function, combined with his subjective perception of the probability of each outcome, $\boldsymbol{P}\left(\boldsymbol{x}_{i}\right)$. The subjective expected utility is defined as:

$$
\mathrm{U}=\sum_{i=1}^{n} P\left(x_{i}\right) u\left(x_{i}\right)
$$

Eq. 5 represents the perceived utility of a planned action (an intended action that has not yet occurred) similarly to how Eq. 4 represents the expectations of successful outcome of all future actions, both defined and undefined.

Eq. 4 also allows introduction of new quantitative methods in research on SWB. In technical disciplines, multiplication of the probability of a specific event (e.g., probability of satisfying a need) by the resulting consequences of such event (e.g., weight of the need) is generally defined as a risk [39]. Normally a risk has negative connotations as it is related to the probability of an adverse event. Eq. 4 gives the probability of the occurrence of a positive event (satisfaction of a need), and therefore defines an opportunity rather than a risk. Risk/opportunity (rewards) analysis is a well-developed knowledge tool widely utilised in business, finance, military planning, and a broad range of technical disciplines.

Applying risk analysis to the study of well-being provides an opportunity to expand the range of available methods in the research on SWB. The advantage of the proposed approach is that it allows examination of the separable components of SWB, related to a wide range of needs. One of the most widely used risk analysis techniques is based on application of the risk/opportunity matrix [40]. A proposed risk/opportunity matrix for assessing levels of SWB associated with a particular need is presented in Table 1. The vertical axis of the matrix represents the relative weight of the need, whilst the horizontal axis denotes assessed likelihood of its satisfaction. The number of segments in the vertical and horizontal axes is dependent on application and user preferences. The criticality of a need can be segmented in intervals between very low and very high. Similar segments can be applied to the likelihood of satisfying a need, e.g., highly unlikely, unlikely, possible, likely, highly likely. Weighted levels of satisfaction for categories of needs can then be summarised to calculate the total level of projected SWB for all dominant categories of needs. Table 1 makes it possible to generate survey questionnaires to be used in the future risk analysis based empirical research of SWB for individuals or groups of people.

\section{Table 1. Level of SWB Matrix.}

\begin{tabular}{|c|c|c|c|c|c|c|}
\hline \multirow{2}{*}{ Relative weight of a need $\mathbf{w}_{\mathbf{i}}$} & \multicolumn{5}{|c|}{ Probability of satisfying a particular need $\mathbf{p}_{\mathbf{i}}$} \\
\cline { 3 - 7 } & & Very Unlikely & Unlikely & Possible & Likely & Very Likely \\
\cline { 3 - 7 } & & $\mathbf{0 - 0 . 2}$ & $\mathbf{0 . 2 - 0 . 4}$ & $\mathbf{0 . 4 - 0 . 6}$ & $\mathbf{0 . 6}-\mathbf{0 . 8}$ & $\mathbf{0 . 8}-\mathbf{1 . 0}$ \\
\hline Very high & $0.8-1.0$ & 0.09 & 0.27 & 0.45 & 0.63 & 0.81 \\
\hline High & $0.6-0.8$ & 0.07 & 0.21 & 0.35 & 0.49 & 0.63 \\
\hline Medium & $0.4-0.6$ & 0.05 & 0.15 & 0.25 & 0.35 & 0.45 \\
\hline Low & $0.2-0.4$ & 0.03 & 0.09 & 0.15 & 0.21 & 0.27 \\
\hline Very low & $0.0-0.2$ & 0.01 & 0.03 & 0.05 & 0.07 & 0.09 \\
\hline
\end{tabular}


Table 2. Level of projected SWB. Case study based on data by Bojanowska \& Zalewska [43].

\begin{tabular}{|c|c|c|c|c|c|c|c|c|c|}
\hline \multicolumn{2}{|c|}{ Need Category } & Health & $\begin{array}{c}\text { Knowledge, } \\
\text { Understanding }\end{array}$ & Work & $\begin{array}{c}\text { Material } \\
\text { Well-Being }\end{array}$ & $\begin{array}{c}\text { Freedom, Self- } \\
\text { Determination }\end{array}$ & Relationships & Other & $\begin{array}{c}\text { Total Integrated Level of } \\
\text { SWB, } \\
\mathbf{H}_{\mathrm{p}}\end{array}$ \\
\hline $\begin{array}{c}\text { Need Tag } \\
\text { Number }\end{array}$ & $\boldsymbol{i}$ & $\mathbf{1}$ & $\mathbf{2}$ & $\mathbf{3}$ & $\mathbf{4}$ & $\mathbf{5}$ & $\mathbf{6}$ & 7 & 7 \\
\hline $\begin{array}{c}\text { Relative weight } \\
\text { of need }\end{array}$ & $\boldsymbol{w}_{\boldsymbol{i}}$ & 0.343 & 0.042 & 0.054 & 0.071 & 0.030 & 0.424 & 0.036 & $\mathbf{7}$ \\
\hline $\begin{array}{c}\text { Level of SWB } \\
\text { for a category } \\
\text { of needs }\end{array}$ & $\boldsymbol{p}_{\boldsymbol{i}} \boldsymbol{w}_{\boldsymbol{i}}$ & 0.216 & 0.027 & 0.034 & 0.045 & 0.019 & 0.267 & 0.021 & $\sum_{\boldsymbol{i}=1} \boldsymbol{p}_{\boldsymbol{i}} \boldsymbol{w}_{\boldsymbol{i}}=\mathbf{0 . 6 3}$ \\
\hline
\end{tabular}

It should be noted that, despite numerous publications on the subject, taxonomy of human needs is yet to be completed. Many classification systems proposed to date originate from the works of Maslow [41] and Deci \& Ryan [42]. The risk analysis-based approach to a definition of SWB is contingent, but not constrained, on the selection of any particular system for classification of needs.

\subsection{Application of Risk Analysis in Computation of Projected SWB}

In this section we present an example of how the risk analysis method can be applied in computation of SWB. We aim to illustrate applications of the method and identify ways to further develop it. For that purpose, we will use data from a study by Bojanowska \& Zalewska [43] of lay understanding of happiness. Since available information is obtained outside the premise of risk analysis methodology, certain assumptions will have to be applied in order to complete the case.

Bojanowska \& Zalewska [43] conducted a study of lay understanding of happiness for different need categories defined by Eurostat [44]; health, knowledge/understanding, work, material well-being, freedom/self-determination, relationships. The study is especially interesting as it measures relative weights of the various needs for a group of individuals. The authors conclude that two specific categories of needs stand out as the most dominant in defining happiness; health, with a relative weight of $34.3 \% \quad(\boldsymbol{w}=0.34)$, and social relationships, with a relative weight of $42.4 \%(\boldsymbol{w}=0.42)$. The reported mean value of life satisfaction on a 7-point scale (Diener et al. 1985) was 4.4. The equivalent value of life satisfaction adjusted to a 10-point scale is 6.3. Earlier in this paper we hypothesise that measurements based on the life satisfaction scale and the risk analysis theory may produce similar or identical results (with due adjustment for different scales). If this assumption is correct, life satisfaction of 6.3 corresponds to an $\mathbf{H}_{\mathbf{p}}$ coefficient value of 0.63 . Subsequently, Bojanowska \& Zalewska's findings can be used to illustrate the methodology for assessing happiness levels based on separate categories of needs. As assessment of probabilities of satisfaction of needs was not considered in the research, the same aggregated probability value is implicitly assumed for all categories of needs. With this assumption in mind, study data on relative need weights allows to generate a numerical data set Table (2) for the separable components of happiness for specific categories of needs. The derived subjective levels of happiness related to particular categories of needs range from 0.019 for freedom/self-determination needs to 0.267 for relationships needs. We posit, that in the future existing SWB research methodology [43] can be adapted for application of the risk analysis method by expanding survey questionnaires to include a section on personal assessment of probability of full satisfaction of particular categories of needs as defined in Table (1).

\section{MOMENTARY SWB VS PROJECTED SWB}

So far, we have conceptualised two states of SWB, momentary SWB and projected SWB, which are complementary to each other, but self-contained in their origin. SWB is a combination of the two states. The balance between different types of SWB is unique for each individual and depends on many factors, including social environment, age, gender, life experiences, health, etc.; momentary SWB depends on short term results, whilst projected SWB focuses on process and future goals. These approaches represent the two different philosophies applied to definitions of success in various social contexts.

The notion of momentary SWB and projected SWB correlates closely with. Zimbardo's work $[45,46]$ on time perspectives, especially concerning present and future orientated personalities. However, it should be noted that Zimardo's views are, to some extent, influenced by cultural bias, as he goes as far as to claim that "future orientation has been related to many positive consequences for individuals in Western society, such as higher socioeconomic status, superior academic achievement, less sensation seeking, and fewer health risk behaviours. The opposite holds for those with a dominant present orientation, who are seen as at risk for many negative life consequences, among them mental health problems, juvenile delinquency, crime, and addictions, when they function in a predominantly future-oriented society". In our opinion such inequitable preference towards future orientation can be misleading and is not necessarily supported by statistical analysis of the level of happiness across different cultures [47].

If projected $S W B \mathbf{H}_{\mathbf{p}}$ is defined as the combined probability of satisfying future needs, and variation in momentary $S W B$ $\Delta \mathbf{H}_{\mathrm{m}}$ is defined as the change in the level of SWB resulting from an action, then these two parameters are not necessarily deterministically dependent on each other. Few actions have direct impacts on long term projected $S W B$. Entering into a romantic relationship is an example of a long lasting positive impact of a particular action on long term SWB. A professional athlete's decision to retire and terminate his sports career is an example of an action with a potentially detrimental impact. More often than not, there is an indirect influence of actions on the $\mathbf{H}_{\mathbf{p}}$ value. This is enabled through the feedback mechanism, when actions affect life experience and catalogue of dominant needs of an individual.Life experience is origi- 
nally established based on the results of completed activities, and then used as a reference in risk analysis of satisfaction of future needs. The interrelation between momentary results of actions and acquired personal experience can be complex. For example, restrictions imposed on a child by an over-caring parent may produce a positive impact on the child's momentary well-being, but nevertheless can have adverse implications on its long-term SWB through the development of passive behavioural patterns adversely affecting the potential for the satisfaction of certain needs in the future. The experience database, whilst accumulating past experiences, also consolidates attitudes, social norms and cultural predispositions. The individual experience database is highly affected by personality traits, as different personality traits lead to different conclusions, when evaluating practical experiences. As a result, someone more optimistic in nature may tend to value his chances in satisfying future needs higher than someone who is more pessimistically inclined.

Transient actions can also influence long term well-being by altering the catalogue of dominant needs. In that respect interrelations between effect of actions on momentary and projected SWB may be quite intricate as well. Schwarz \& Strack demonstrate that the same event may influence evaluations of one's life as a whole and evaluations of specific domains in opposite directions [35]. For example, an extremely positive event in domain X may induce a good mood, resulting in reports of increased well-being. However, the same event may also increase the standard of comparison used in evaluating domain $\mathrm{X}$, resulting in judgments of decreased satisfaction with this particular domain.

$\Delta \mathbf{H}_{\mathrm{m}}$ and $\mathbf{H}_{\mathrm{p}}$ parameters can be illustrated by the time domain diagram of SWB Fig. (2), which defines the momentary level of SWB for completed activities and expected levels of SWB for outcomes of future possible actions. Lapsed momentary SWB fluctuates frequently in response to transient life experiences.A change in SWB levels caused by a particular action/event is equal to $\Delta \mathbf{H}_{\mathrm{m}}$, which is either positive or negative, and either momentary or longer lasting. The latter would occur in case of a protracted activity, such as attending a sports event or a visit to the dentist. As mentioned earlier people spend most of their time in a semi-active state, such as periods of mind-wandering or recovering from a change in the emotional state on the back off a recently completed action. This condition is illustrated in Fig. (2), by the dotted line. Anticipated future SWB $\mathbf{H}_{\mathrm{p}}$, represented by the dashed line, is depicted as having a constant value. However, for some future events (e.g., medical procedures, participation in charity events, purchasing a house) one can anticipate fluctuations in the future level of SWB as well.

Our proposed concept of two states of SWB, with corresponding coefficients of SWB $\mathbf{H}_{\mathrm{p}}$ and $\Delta \mathbf{H}_{\mathrm{m}}$, correlates with known distinctions between short-lived happiness and enduring well-being [48]. Overlaps between different theories

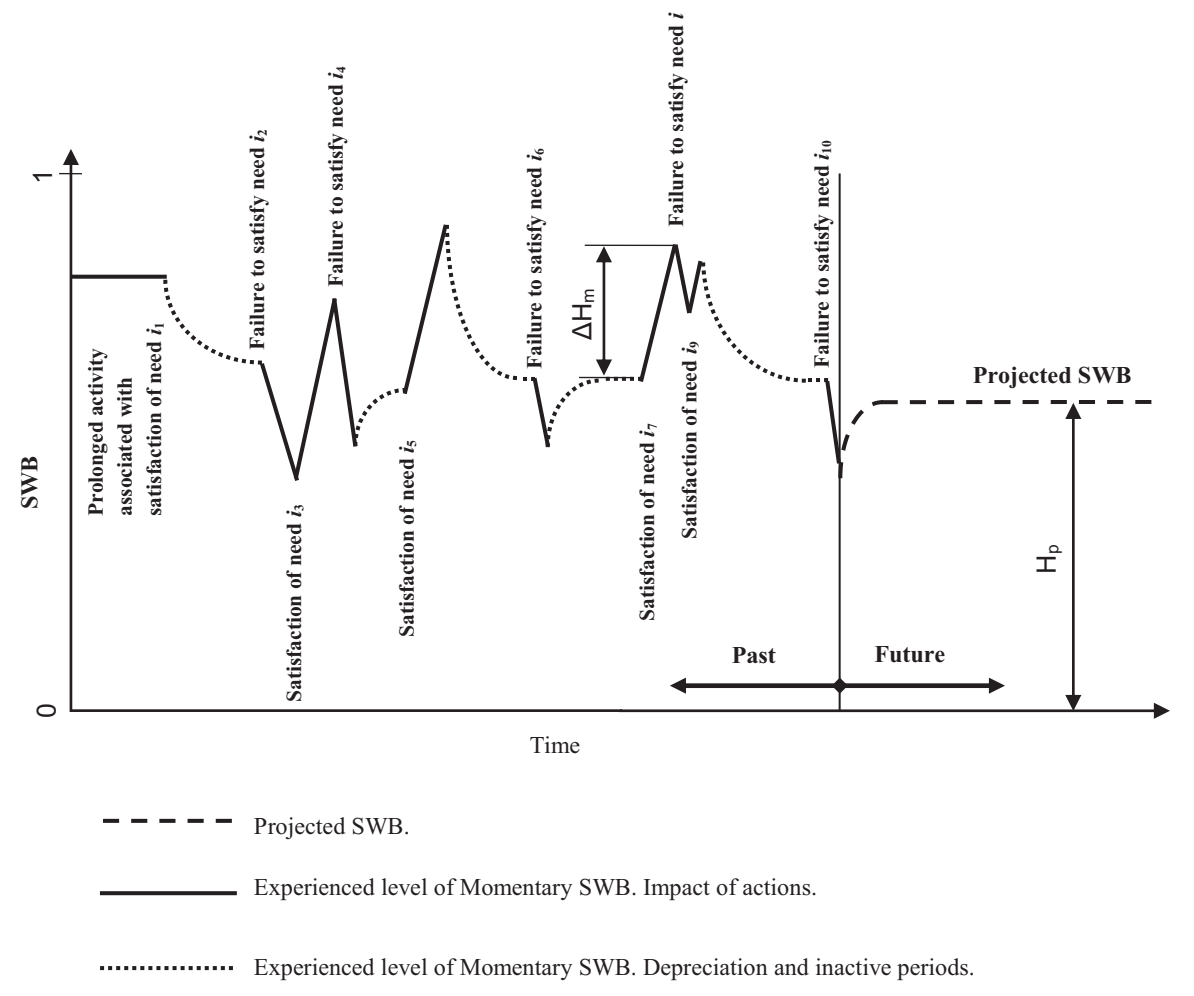

Fig. (2). Typical Time Domain Diagaram of SWB. 
of happiness are not coincidental as they ultimately originate from or can be related to the algorithm of human behaviour.

\section{CORRELATION WITH OTHER THEORIES OF SWB}

Diener, Oishi, \& Lucas [16] categorise SWB theories according to three groups; need and goal satisfaction theories, process or activity theories, and genetic and personality predisposition theories. They provide summaries of the three approaches, synopsised in the following paragraphs.

Proponents of need and goal satisfaction theories centre on "the idea that the reduction of tensions lead to happiness. Freud's [49] pleasure principle and Maslow's [41] hierarchical needs model represent this approach". It follows that "need and goal satisfaction theorists argue that the reduction of tension and satisfaction of biological and psychological needs and goals will cause happiness".

The second group, proponents of process or activity theories, consider that "engagement in an activity itself provides happiness. Most notably, Csikszentmihalyi [50] suggested that people are happiest when they are engaged in interesting activities that match their level of skill. He called the state of mind that results from this matching of challenges and skill, flow, and argued that people who often experience flow tend to be very happy". As such, "both needs theorists and activity theorists argue that subjective well-being will change with the conditions in people's life".

Supporters of the third approach, genetic and personality predisposition theories, point to "an element of stability in people's levels of well-being. These theorists argue that subjective well-being is strongly influenced by stable personality dispositions", and that "although life events can influence subjective well-being, people eventually adapt to these changes and return to biologically determined set points or adaptation levels" [51]. However, there is little evidence supporting ideas of full adaptation to set points irrespective of life circumstance [12]. On the other hand, individual-level partial adaptation to life events is a normal feature of the human psyche. Significant research is being conducted into identifying the mechanism of such adaptation $[1,4]$.

Eqs. 2, 3, and 4 exemplify that Maslow's theory of needs is at the core of our proposed model. At the same time, whilst we describe SWB as a reflection on the process of satisfaction of needs, it is not accidental that our proposed approach correlates with the process theories of SWB as well. These theories are based on the rationale of balance between individual skills and challenges $[50,52]$. Within our model this balance is achieved through a feedback mechanism between outcome of actions and catalogue of dominant needs Fig. (1). As we have previously shown, even satisfaction of needs may in the longer run have a disruptive effect on happiness and create a psychological distortion. Thus, in order to maintain a state of happiness it is advantageous to establish a life pattern characterised by a sustainable balance between outcomes of actions and ever changing catalogue of dominant needs. Hence, within the context of our model, conditions of flow occur when an individual is engaged in long lasting and fulfilling activities, while maintaining (or enhancing) a desire to continue with these activities through a feedback mechanism. Development of the process theories of happiness eventually resulted in the emergence of positive psychology [53]. Within the branch of positive psychology, Seligman [54] devised the concept of PERMA (Positive emotion; Engagement; Relationships; Meaning; Achievement), which transforms a theoretical model to practical application aimed at enhancing quality of life.

Focus on long term balance between needs and outcomes of actions is at the core of the hedonic adaptation theories of SWB. Sheldon and Lyubomirsky [4], the developers of the Hedonic Adaptation to Positive and Negative Experience (HAPNE) model, postulate that adaptation to positive and negative life experiences [1] "proceeds via two separate paths, such that initial well-being gains or drops corresponding to a positive or negative life change (e.g., relationship start up vs. breakup) are eroded over time. The first path specifies that the stream of positive or negative emotions resulting from the life change (e.g., joy or sadness) may lessen over time, reverting people's happiness levels back to their baseline. The second, more counterintuitive path specifies that the stream of positive or negative events resulting from the change may shift people's expectations about the positivity (or negativity) of their lives, such that the individual now takes for granted circumstances that used to produce happiness or is inured to circumstances that used to produce unhappiness." Both adaptation paths of the HAPNE model can be fully integrated into our model of human happiness. The lessening of impacts of actions on momentary SWB is taken into account by the forgetting factor $\boldsymbol{\Upsilon}_{\mathbf{i}}$ in Eqs. 2 and 3 for momentary SWB. The second compo-nent, deflation of repetitive experience, is modelled through a feedback mechanism linking action outcomes to changes in the catalogue of dominant needs. Existence of such a feedback mechanism results in a situation where unless a condition of flow is encountered, successful but repetitive action may diminish the ranking of needs triggering them in the first place, consequently devaluing relative need weight $\boldsymbol{w}_{\boldsymbol{i}}$ (Eqs. 2, 3, and 4), and impairing increases in momentary SWB $\Delta \mathbf{H}_{\mathrm{m}}$ for repetitive actions.

In summary, need satisfaction, process, and individuallevel partial hedonic adaptation theories of SWB can be modelled within the framework of our model. We consider that they represent specific instances of a generalised theory based on the analysis of the process of satisfaction on needs. Development of a general concept is possible as we do not attempt to posit a unique standalone theory of SWB, but rather derive it from the algorithm of human behaviour. The idea that multiple theorises of SWB can be combined within the premise of a unified concept leads to the conclusion that there is no universal way for enhancement of happiness, but rather numerous paths to its achievement. This is in line with the understanding of happiness proposed within the framework of the Self-Determination Theory, which is posited as a macro theory of human motivation, development, and health [55].

While proposed model of SWB originates from existing theories, it contains a number of novel and distinguishing features. Firstly, we postulate that the foundation of any model of SWB should be based on the model of human behaviour. Such an approach allows evaluation of well-being in dynamic settings of a constantly transforming individual acting in the 
ever changing physical and social environments. Secondly, we conceptualise that SWB consists of separable components associated with different needs and time perspectives. All these components of SWB are derived based on the same algorithm and, overall SWB can be evaluated through analysis of distinct elements. Thirdly, the model is built on the premise of risk analysis theory. Risk analysis is an advanced analytical method used in a variety of applications with high potential for enhancement of SWB science. Lastly, the proposed model is impartial as it does not favour or advocate any specific course of actions but rather puts emphasis on a diversity of strategies for attainment of happiness.

\section{LIMITATIONS AND FUTURE RESEARCH}

The proposed model of SWB represents a theoretical construct. Further empirical research is required for its verification and validation. The most compelling research study may perhaps be further enhancement of the risk analysisbased apparatus in application to the science of well-being, and more specifically, in evaluation of projected SWB. We believe that the proposed methodology exemplified by eq. 4 and Tables $1 \& \mathbf{2}$ is sufficiently developed to allow for its implementation in empirical verification. The research should address computation of projected SWB for individuals or groups of people in accordance with existing SWB measurement methodology [43] extended by the survey of personal assessment of probability of satisfaction of needs. Such research would allow to test our hypothesis that Life Satisfaction and projected SWB are highly correlated parameters. If that is indeed the case, then this may potentially open the possibility for a new way of computing Life Satisfaction and analyse its separable components with enhanced precision.

In its present form the postulated model focuses on the processes of change in SWB and not on evaluation of levels of well-being. Nevertheless, as demonstrated earlier, a methodology for computation of projected SWB can be clearly conceived. To an extent this is due to the proposition, that in the long-term perspective, individuals develop a rather steady and integrated (combining cognitive and affective components) picture of deferred needs and probabilities of their satisfaction. The situation with evaluation of momentary SWB is more complex. The proposed functional eq. 3 for momentary SWB identifies parameters affecting momentary well-being but does not offer a practical method for its computation. The main stumbling block is related to the fundamentals of definition of SWB [16], which is described as "a person's cognitive and affective evaluation of his or her life". It is not clear how separable momentary cognitive and affective components can be merged and how can they be measured or computed. Perhaps, the segregation into two types of evaluation obscure, rather than enhances the definition of SWB. Some authors attempt to move away from such constructs, either by ignoring them or advocating for the use of an overall "subjective happiness" $[30,56]$. Until recently, little research has been conducted into the interrelation and balance between affective and cognitive components of happiness. Another complication in computation of momentary SWB arises due to the proposed notion that momentary need relative weight, or potency, is not a constant but a variable parameter. A methodology for quantified assessments of momentary need relative weight (potency) ought to be progressed before computation of momentary SWB can be attempted.

Within the premise of this paper we have touched upon several subjects extending beyond the topic of well-being. One of them is categorisation of human needs. As previously mentioned, despite numerous publications addressing the matter, taxonomy of human needs is yet to be completed. The risk analysis based approach to a definition of SWB is contingent, but not constrained, on the selection of any particular system for classification of needs. Nevertheless, advancement in taxonomy of human needs would enhance proposed SWB model, which is based on evaluation of components associated with separable categories of needs. Further research on needs' potency and its dependency on life circumstances would be also highly beneficial.

\section{MAIN FACTORS AFFECTING HAPPINESS}

Attaining happiness is a lifelong undertaking which occurs within a dynamic, continuously changing environment. Changes in life circumstances result in perpetual modifications to the list of dominant needs, the reorganisation of which necessitates adjustments to tactics and strategy for attaining happiness. Traditionally, theories of happiness emphasise specific mechanisms or a set of measures for enhancement of life quality. However, generally happiness originates from certain basic common postulates. Based on the definition and analysis of SWB by Diener et al. [16, 57], further elaborated by us in Eqs. 3 and 4, it can be précised that happiness is enhanced through the following means:

- Increase in frequency of positive experiences,

- Increase in magnitude of transient positive experiences,

- Decrease in frequency of negative experiences,

- Decrease in magnitude of transient negative experiences,

- Increase in level of self-evaluation regarding future projected life events.

All stages in the algorithm of human behaviour Fig. (1), may impact the state of happiness. Missed or incorrectly interpreted signals, inadequately assessed risks, poorly constructed plans, or faultily executed actions may all influence SWB levels. Performance efficiency in each algorithm phase is affected by an individual's physical, psychological, and cognitive capabilities. For a standalone action, taken in isolation from personal disposition and life circumstances, physical and cognitive skills appear to have a decisive role in forging success and happiness. However, subjectively, success is always calibrated against an individual's needs. Identification of priority needs, which are manifested through wants, goals, aspirations and dreams, plays a crucial role in defining an individual's SWB. This is especially evident in the case of projected needs, for which the execution stage does not exist (as the need is foreseen but no immediate action is undertaken), and signal detection, signal assessment and planning phases are significantly subdued. In 
this case, likelihood of future success is determined primarily by defining dominant needs and secondly by chances of their satisfaction, as estimated through risk assessment. The highest levels of evaluation of life quality satisfaction is attained when needs are highly correlated with the abilities required to achieve them. Fine-tuning the balance between needs and skills is one of the functions of the human psyche.

As discussed in this paper, happiness is a complex phenomenon; it consists of many components associated with separable needs, it accounts for both momentary and projected perspectives, and there are many different paths for its enhancement. As such, there is no one size fits all solution for its attainment. Examples of some common happiness enhancement strategies include:

- Improving skills in order to increase chances of satisfaction of needs,

- Increase frequency of engagement in desirable activities to increase frequency of positive affect,

- Managing needs by lowering expectations and improving chances of their satisfaction,

- Managing needs to increase complexity of challenges in order to increase magnitude of positive affect and improve cognitive self-evaluation,

- Avoidance of challenges to minimise negative affect,

- Establishing a long-lasting balance between challenges and skills (e.g., attaining "flow"),

- Developing personality traits that enhance positive life attitude and self-confidence,

- Passively hoping for positive outcomes (hoping for luck).

Choosing a specific happiness strategy highly depends on life circumstances, e.g., experiences, social and physical environments, health, age and gender. Certain happiness strategies may also be viewed as controversial, e.g., religious asceticism or extreme risk taking. In the case of religious asceticism, it is a technique to manage needs, where happiness is expected to be attained through wilful obliteration of needs that are otherwise mostly considered essential to individuals. It aims to increase frequency and magnitude of positive affects, improve chances of satisfaction of future needs, and is achieved by reducing the variety and complexity of needs by focussing on a smaller number of needs. Similarly, extreme risk taking aims to increase frequency and magnitude of positive affects and satisfy future needs - but, this is achieved through deliberately complicating life circumstance, for example through seeking challenging physical environment (e.g., skydiving).

Some strategies may result in a failure or be counterproductive. For example, durable withdrawal from social enggements may be an individual's strategy to reduce frequency of negative affect as a defensive reaction to dissatisfaction with experiences of social interactions.

\section{CONCLUSION}

In this paper we propose a model of human SWB, which we refer to as an individual's cognitive and affective evaluation of his/her life that occurs through the process of satisfaction of needs. We use the terms happiness and subjective well-being synonymously.

SWB encompasses affective and cognitive perspectives and can be divided into separable components associated with separable needs. Needs are categorized as being either momentary (current) or projected (future expected or deferred) needs. Consequently, we discuss momentary and projected SWB; the former a measure of satisfaction with transient life experiences, the latter a reflection on expected integrated probability of satisfaction of future needs, which is established based on analysis of risks to achieving these needs. We depict momentary and projected SWB through a time domain diagram, where multiple different components of SWB are interlinked, but are not necessarily deterministically dependent on each other. Attainment of satisfaction of needs is represented by the algorithm of human behaviour according to which satisfaction of needs is achieved through a sequence of steps: 1) detection of signal, 2) assessment of signal, 3) risk analysis, 4) planning, and 5) execution of action. The algorithm also contains regulating blocks - the catalogue of dominant needs and life experience database, which govern signal assessment and risk analysis stages, respectively. All actions alter momentary levels of SWB at an impact proportional to the ratio of success and the weight of the needs triggering the action as subjectively assessed by an individual. The impact of an action on momentary levels of SWB dissipates over time. The algorithm of human behaviour includes a number of feedback loops. These feedback mechanisms exhibit dynamic and non-linear interrelation between needs, action results, and multiple components of SWB. The complex nature of happiness allows for a variety of strategies for its enhancement. Certain happiness strategies may result in failure. Individual's selection of a strategy for happiness is based on life experiences and intrinsic circumstances.

We propose that the current widely recognised need satisfaction, process, and individual-level partial hedonic adaptation theories of SWB can be modelled within a unified concept framework, and that they represent separate instances of an integrated theory of SWB that is enabled by the algorithm of human behaviour.

\section{LIST OF ABBREVIATIONS}

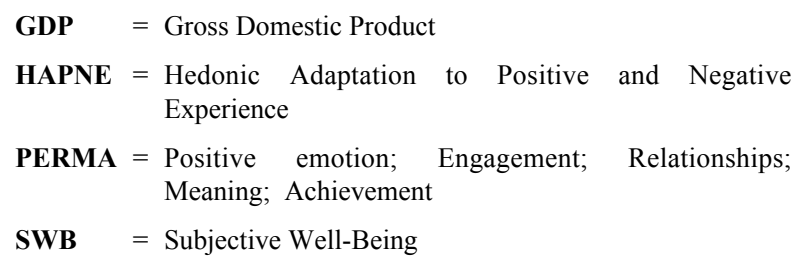

ETHICS APPROVAL AND CONSENT TO PARTICIPATE

Not applicable.

\section{HUMAN AND ANIMAL RIGHTS}

No animals/humans were used for studies that are basis of this research. 


\section{CONSENT FOR PUBLICATION}

Not applicable.

\section{CONFLICT OF INTEREST}

The authors declare no conflict of interest, financial or otherwise

\section{ACKNOWLEDGEMENTS}

Declared none.

\section{REFERENCES}

[1] Lyubomirsky S. Hedonic adaptation to positive and negative experiences.The Oxford handbook of stress, health, and coping. New York, NY, US: Oxford University Press 2011; pp. 200-24.

[2] Diener E. The remarkable changes in the science of subjective wellbeing. Perspect Psychol Sci 2013; 8(6): 663-6.

[http://dx.doi.org/10.1177/1745691613507583] [PMID: 26173230]

[3] Csikszentmihalyi M. Flow: The Classic work on how to achieve happiness. London: Rider Books 2002.

[4] Sheldon KM, Lyubomirsky S. Is it possible to become happier? (And, if so, how?). Soc Personal Psychol Compass 2007; 1: 129-45. [http://dx.doi.org/10.1111/j.1751-9004.2007.00002.x]

[5] Dodge R, Daly A, Huyton J, Sanders L. The challenge of defining wellbeing. Int J Wellbeing 2012; 2(3): 222-35.

[http://dx.doi.org/10.5502/ijw.v2i3.4]

[6] Veenhoven R. How Do We Assess How Happy We Are? Tenets, Implications and Tenability of Three Theories.Happiness, economics and politics: Towards a multi-disciplinary approach. 2006; Chapter 3, 45-69.

[7] Maslow AH. A preface to motivation theory. Psychosom Med 1943; 5: 85-92.

[http://dx.doi.org/10.1097/00006842-194301000-00012]

[8] Wilson W. Correlates of avowed happiness. Psychol Bull 1967; 67(4): 294-306.

[http://dx.doi.org/10.1037/h0024431] [PMID: 6042458]

[9] Bradburn N. The structure of psychological well-being. Chicago: Aldine 1969.

[10] Diener E. Subjective well-being. Psychol Bull 1984; 95(3): 542-75. [http://dx.doi.org/10.1037/0033-2909.95.3.542] [PMID: 6399758]

[11] Forgeard MJC, Jayawickreme E, Kern M, Seligman MEP. Doing the right thing: Measuring wellbeing for public policy. Int $\mathrm{J}$ Wellbeing 2011; 1(1): 79-106.

[http://dx.doi.org/10.5502/ijw.v1i1.15]

[12] Helliwell J, Layard R, Sachs J, Eds. World Happiness Report 2015. New York: Sustainable Development Solutions Network 2015.

[13] UN General Assembly Resolution A 65(L): 86.2011 Jul 13;

[14] Rutledge RB, de Berker AO, Espenhahn S, Dayan P, Dolan RJ. The social contingency of momentary subjective well-being. Nat Commun 2016; 7: 11825 .

[http://dx.doi.org/10.1038/ncomms11825] [PMID: 27293212]

[15] Diener E, Suh EM, Lucas RE, Smith HL. Subjective Well-Being: Three Decades of Progress. Psychol Bull 1999; 125(2): 276-302. [http://dx.doi.org/10.1037/0033-2909.125.2.276]

[16] Diener E, Oishi S, Lucas RE. Subjective well-being: The science of happiness and life satisfaction.Handbook of Positive Psychology. Oxford, New York: Oxford University Press 2002.

[17] OECD Guidelines on measuring subjective well-being, OECD Publishing 2013

[18] Shin D, Johnson D. Avowed happiness as an overall assessment of the quality of life. Soc Indic Res 1978; 5(1): 475-92. [http://dx.doi.org/10.1007/BF00352944]

[19] McKay C. What is life? Astrobiology Magazine 2014. 18 September

[20] Galperin PJ. Introduction to psychology. Russian ed. Moscow 1976.

[21] Newell A, Simon HA. Human problem solving. Englewood Cliffs, NJ, USA: Prentice Hall 1972

[22] Newell A. Unified Theories of Cognition. Cambridge, Massachusetts: Harvard University Press 1990.

[23] Boyd JR. Destruction and Creation. U.S. Army Command and General Staff College 1987.

[24] Fishbein M, Ajzen I. Predicting and changing behavior: The Reasoned Action Approach. New York: Taylor \& Francis 2010.

[25] Tay L, Diener E. Needs and subjective well-being around the world. J
Pers Soc Psychol 2011; 101(2): 354-65

[http://dx.doi.org/10.1037/a0023779] [PMID: 21688922]

[26] Murray HA. Explorations in personality. New York: Oxford University Press 1938

27] Stutzer A, Frey BS. Does marriage make people happy, or do happy people get married? J Socio-Economics 2006; 35: 326-47. [http://dx.doi.org/10.1016/j.socec.2005.11.043]

28] Schuyler BS, Kral TRA, Jacquart J, et al. Temporal dynamics of emotional responding: Amygdala recovery predicts emotional traits. Soc Cogn Affect Neurosci 2012.

[http://dx.doi.org/10.1093/scan/nss131] [PMID: 23160815]

[29] Bechtereva NP, Ed. Mechanisms of human brain function Part one Human neurophysiology. Russian ed.. Leningrad: Nauka 1988.

[30] Rutledge RB, Skandali N, Dayan P, Dolan RJ. A computational and neural model of momentary subjective well-being. Proc Natl Acad Sci USA $2014 ; 111(33):$ 12252-7.

[http://dx.doi.org/10.1073/pnas.1407535111] [PMID: 25092308]

[31] Killingsworth MA, Gilbert DT. A wandering mind is an unhappy mind. Science 2010; 330(6006): 932

[http://dx.doi.org/10.1126/science.1192439] [PMID: 21071660]

[32] Affective forecasting. Wilson TD, Gilbert DN. Advances in experimental social psychologyUSA: Elsevier Science 2003; 35: pp. 345-411.

[33] Denes-Raj V, Epstein S. Conflict between intuitive and rational processing: When people behave against their better judgment. J Pers Soc Psychol 1994; 66(5): 819-29.

[http://dx.doi.org/10.1037/0022-3514.66.5.819] [PMID: 8014830]

[34] Epstein S. Integration of the cognitive and the psychodynamic unconscious. Am Psychol 1994; 49(8): 709-24. [http://dx.doi.org/10.1037/0003-066X.49.8.709] [PMID: 8092614]

[35] Schwarz N, Strack F. Evaluating one's life: A judgment model of subjective well-being.Subjective well-being: An interdisciplinary perspective. Oxford: Pergamon 1991; pp. 27-47.

[36] Savage LJ. The Foundations of Statistics 1954.

[37] Ramsey FP. Truth and Probability.Chapter VII in The Foundations of Mathematics and other Logical Essays, Reprinted 2001, Routledge 1931; ISBN 0-415-22546-9

[38] Von Neumann J, Morgenstern O. Theory of Games and Economic Behavior. Princeton Univ. Press 1944.

39] Deci EL, Ryan RM. The 'what' and 'why' of goal pursuits: Human needs and the self-determination of behavior. Psychol Inq 2000; 11 : 227-68.

[http://dx.doi.org/10.1207/S15327965PLI1104 01]

[40] NASA. Goddard Space Flight Center, Risk Management Reporting, GSFC-STD-0002 2009.

[41] Maslow AH. Motivation and personality. Ney York: Harper and Row 1970.

[42] Deci EL, Ryan RM. The 'what' and 'why' of goal pursuits: Human needs and the self-determination of behavior. Psychol Inq 2000; 11: 227-68.

[http://dx.doi.org/10.1207/S15327965PLI1104_01]

[43] Bojanowska A, Zalewska AM. Lay understanding of happiness and the experience of well-being: Are some conceptions of happiness more beneficial than others? J Happiness Stud 2015.

[http://dx.doi.org/10.1007/s10902-015-9620-1]

[44] Eurostat. Well-being indicators. Feasibility study. Results of critical review. Paper presented at the 8 th meeting of the working group on sustainable development, Luxembourg 2010.

[45] Zimbardo PG, Boyd JN. Putting Time in Perspective: A Valid, Reliable Individual-Differences Metric. J Pers Soc Psychol 1999; 77 1271-88.

[http://dx.doi.org/10.1037/0022-3514.77.6.1271]

[46] D'Alessio M, Guarino A, DePascalis V, Zimbardo PG. Testing Zimbardo's Stanford Time Perspective Inventory (STPI) -Short Form, Time and Society 2003; VOL. 12 No. $2 / 3$ (2003)

[47] Helliwell J, Layard R, Sachs J, Eds. World Happiness Report 2017 New York: Sustainable Development Solutions Network 2017

[48] Davidson RJ, Schuyler BS. Neuroscience of happiness World happiness report The earth institute. Columbia University 2015; pp. 88-105.

[49] Freud S. New introductory lectures on psychoanalysis. The complete psychological works. New York: Norton 1976; Vol. 16. (Original work published 1933)

[50] Csikszentmihalyi M. Beyond boredom and anxiety. San Francisco: Jossey-Bass 1975

[51] Headey B, Wearing A. Understanding happiness: A theory of subjective well-being. Melbourne: Longman Cheshire 1992. 
[52] Cummins R. Subjective wellbeing, homeostatically protected mood and depression: A synthesis. J Happiness Stud 2010; 11: 1-17.

[http://dx.doi.org/10.1007/s10902-009-9167-0]

[53] Seligman MEP, Csikszentmihalyi M. Positive psychology. An introduction. Am Psychol 2000; 55(1): 5-14.

[http://dx.doi.org/10.1037/0003-066X.55.1.5] [PMID: 11392865]

[54] Seligman ME. Flourish: A visionary new understanding of happiness and well-being. Simon and Schuster 2012

[55] Deci EL, Ryan RM. Facilitating optimal motivation and psychological well-being across life's domains. Can Psychol 2008; 49: 14-23.

[http://dx.doi.org/10.1037/0708-5591.49.1.14]

[56] Lyubomirsky S, Lepper HS. A measure of subjective happiness: Preliminary reliability and construct validation. Soc Indic Res 1999; 46: 137-55.

[http://dx.doi.org/10.1023/A:1006824100041]

[57] Diener E, Sandvik E, Pavot W. Happiness is the frequency, not the intensity, of positive versus negative affect.Assessing well-being. Springer Netherlands 2009; pp. 213-31.

[http://dx.doi.org/10.1007/978-90-481-2354-4_10]

\section{(C) 2019 Kopsov Igor}

This is an open access article distributed under the terms of the Creative Commons Attribution 4.0 International Public License (CC-BY 4.0), a copy of which is available at: (https://creativecommons.org/licenses/by/4.0/legalcode). This license permits unrestricted use, distribution, and reproduction in any medium, provided the original author and source are credited. 